\title{
Building Mass Spectrometers and a Philosophy of Research
}

\author{
J. W. Amy, W. E. Baitinger, and R. G. Cooks \\ Department of Chemistry, Purdue University, West Lafayette, Indiana, USA
}

\begin{abstract}
Development of the techniques of ion kinetic energy spectrometry and mass-analyzed ion kinetic energy spectrometry is described. The extension of these concepts to the method of tandem mass spectrometry for direct mixture analysis is traced, and a rationale for the construction of hybrid mass spectrometers is presented. Collisions of polyatomic ions with surfaces are discussed as an outgrowth of gaseous collisions. An attempt is made to describe a philosophy of research that guided the construction of a dozen mass spectrometers and the exploration of organic ion chemistry in as many contexts. (J Am Soc Mass Spectrom 1990, $1,119-128$ )
\end{abstract}

$\mathrm{T}$ This paper has two major sections, each of which reflects areas in which John Beynon blazed trails. The first section deals with developments in the Aston Laboratory during John Beynon's years here. This material is in some ways a review of the work spawned by John Beynon during our association with him in a heady period that saw extensive work on ion structures and reaction mechanisms by kinetic energy release and energy loss measurements, and on chargechanging collisions in the kilovolt range. It also saw the construction of the reverse-geometry mass-analyzed ion kinetic energy (MIKE) spectrometer together with the fertile research plain to which it yielded access.

The second section is a somewhat didactic presentation of the research philosophy we have practiced at Purdue. New instruments and ancillary techniques as well as fundamental studies and applications are described and interrelated. We do not suggest that our approach is exportable, merely that in a particular place and over a rather extensive period it has proven a successful means of making sense of the barrage of demands and possibilities that is academic research. These modi operandi have evolved over time, and John Beynon's contributions have been a notable ingredient. Naturally, the practice of a research philosophy often falls short of the theory; we note with regret that we continue to this day invariably to have time enough to do a job twice but seldom time enough to do it properly.

\section{The JHB Era}

\section{John Beynon at Purdue}

John Beynon accepted a position as professor of chemistry and director of the Mass Spectrometry Center at Purdue in January 1969. He took the position on a

Address reprint requests to R. G. Cooks, Department of Chemistry, Purdue University, West Lafayette, IN 47907. leave of absence from ICI (Manchester), and in late 1970 he returned to ICI but retained his Purdue chair and spent up to four months a year at Purdue through the period 1971-1975.

During this entire time he worked closely with Jonathan W. Amy, professor of chemistry and director of instrumentation, and with William E. Baitinger, instrument specialist. He also enjoyed the strong support of the head of the department, the late Joseph F. Foster. Richard M. Caprioli played an important role as a collaborator, first as a postdoctoral research associate and then as an assistant professor in the biochemistry division of the chemistry department. The department's precision machinist, the late Thomas E. Ridley, was also closely associated with the Mass Spectrometry Center. John Beynon's first student was Teodor Ast, of Belgrade, who completed a Ph.D. in analytical chemistry during the period 1969-1972. Other Ph.D. students were Thomas Keough (1975) and James F. Elder, Jr. (1976), and James F. Litton (Ph.D. 1976) and David L. Kemp (Ph.D. 1976) both commenced their studies under John Beynon. Postdoctoral students Michael Bertrand from Montreal, K. C. Kim from Korea via Kansas State, E. Grant Jones from Toronto, and D. Thomas Terwilliger from Yale all made important contributions, especially to the physical aspects of the work. Others associated with the Center, which was initially an NIH Regional Research Resource and subsequently NSFfunded, included William Budde, Lloyd Hendricks, Miran Medved, Wilford Perry, Thomas Elwood, and Brad Spenser. Graham Cooks left Kansas State University to become assistant director of the Center early in 1971.

\section{The RMH-2 Mass Spectrometer: Phoenix from the Ashes}

The Hitachi Perkin-Elmer RMH-2 double-focusing mass spectrometer [1] had been designed and built to specifications conceived by Fred W. McLafferty. This 


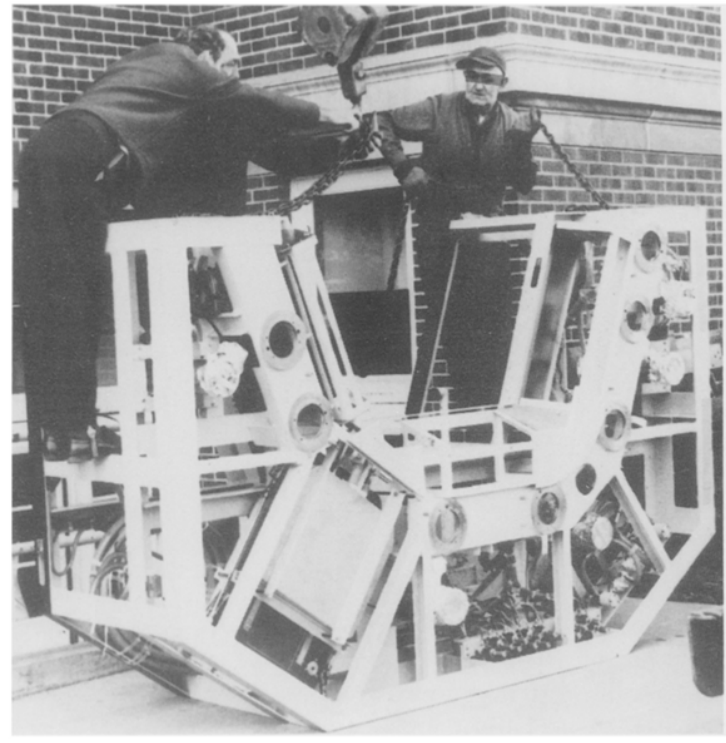

Figure 1. RMH-2 mass spectrometer arrives at Purdue, 1968.

instrument was intended to be the first of a new generation of "super" high-resolution instruments designed also to achieve high sensitivity through use of a modified Nier-Johnson geometry, a $10-\mathrm{kV}$ accelerating potential, and an ion beam path length of over $3 \mathrm{~m}$. This large instrument had three long field-free regions and four slits that could be positioned during operation; moreover, it was built on top of a large metal frame, with the entire flight path accessible for modifications. The instrument arrived at Purdue in 1968 (Figure 1), shortly before Fred McLafferty's departure for Cornell and John Beynon's arrival. Tom E. Noda and T. Komatsu of Hitachi interacted with the Purdue group and supplied the Daruma-the patron god of the instrument-whose eyes were painted to celebrate the first ion beam. The instrument was to achieve a resolution in excess of $10^{5}$, albeit with disappointingly low sensitivity owing to a lack of second-order aberration corrections in the ion optics.

The understanding of this problem almost coincided with the suggestion of Al Struck and Will Major of Perkin-Elmer [2] that information on metastable ions might be obtained by scanning the electric sector voltage in a double-focusing instrument. The RMH-2 instrument, with an electric sector of large radius (500 $\mathrm{mm}$ ) and extremely precise slits, was capable of excellent ion kinetic energy resolution ( $1 \mathrm{eV}$ in 8000 ). These factors led the Purdue group to develop ion kinetic energy spectrometry (IKES) as a method of characterizing the products of metastable ion dissociation and obtaining physicochemical information on these reactions [3-5]. These developments were celebrated by printing political campaign-style buttons reading "Purdue Boilermakers Like IKES." (For younger readers, Dwight D. Eisenhower was reelected President of the United States in 1956 to the slogan "I Like Ike.")
Instrumentally, the IKES capability was achieved quite simply by installing a movable electron multiplier that could be lowered into the ion beam after the beta slit or raised to remove it from the flight path, so allowing passage through the magnetic sector. The modification was done by inserting the bellows assembly of a vacuum valve into the flight tube and attaching a 14stage beryllium-copper electron multiplier to the end of the bellows. When metastable decomposition occurs in a field-free region following acceleration, a focused, nearly monoenergetic, beam of daughter ions is produced. In this technique the sector voltage is scanned from some fixed value to zero, successively bringing to focus ion beams of various energies and so allowing their detection with the multiplier in position behind the energy-resolving beta slit. Thus IKES provided a technique for obtaining energy spectra without mass analysis.

For a number of years, mass spectrometer designers had taken pains to remove metastable ions from recorded spectra. In the mid-1960s, several workers, among them William Chupka, Jean Futrell, Keith Jennings, Fred McLafferty, and Dudley Williams, made concerted attempts to identify and observe metastable ions, the "underdogs," as Professor Beynon called them. John Beynon's innovation was to see the unimolecular fragmentation of an ion $\mathrm{m}_{1}^{+}$to give fragments $m_{2}^{+}$and $m_{3}$, not only in terms of the massto-charge ratios of the species involved but also in terms of energy balance. This viewpoint had earlier led him to derive the relationship between metastable peak widths and the internal energy released as translational energy upon fragmentation [6]. Now, with a powerful tool for measuring translational energies of ion beams, a new area of research opened up (Figure 2).

The IKES method allowed isomeric compounds to be characterized by the various metastable transitions observed for each isomer. Unimolecular fragmentations of ions $\left(\mathrm{m}_{1}^{+}\right)$generated in the ion source to give daughters $m_{2}^{+}$are shown as peaks at a position given by the fraction $m_{2} / m_{1}$ in the IKE spectrum. Although there is the possibility of misassignment of a transition in the absence of an independent measurement of mass, these experiments made a considerable contribution to addressing questions of ion structure and reaction mechanism. Particularly noteworthy were the insights into the rearrangements associated with the fragmentations of simple esters [7] and ketones [8] due to the ability to observe the behavior of specific isotopically labeled molecules. The very high sensitivity of the measurement added greatly to the number of known fragmentations of these and other simple ions.

\section{Peak Shapes}

Even more important was the information contained in the shapes of the individual peaks. It might have been easy to ignore these variations as being secondary to the information on the masses of the fragmenting ions 


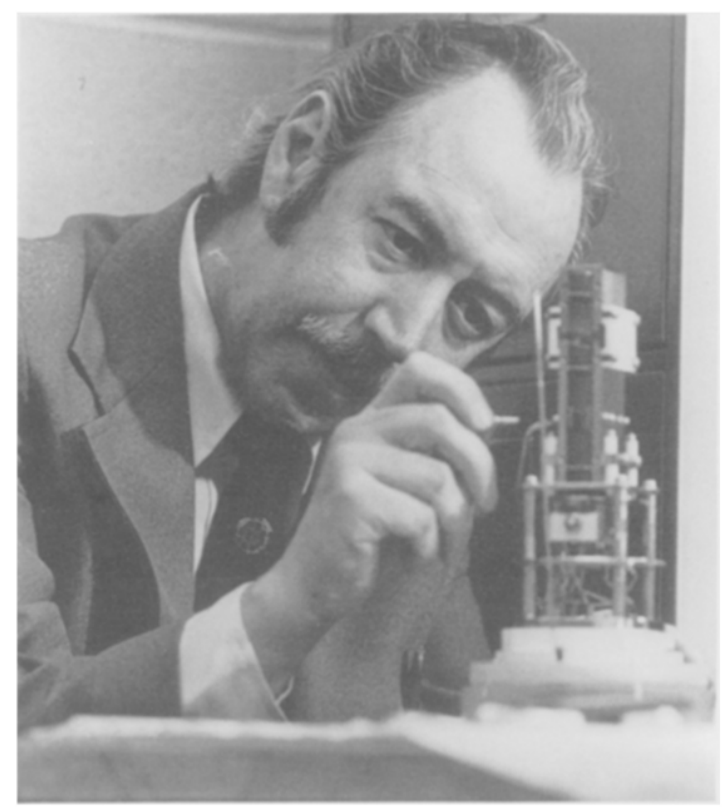

Figure 2. John Beynon at work on the ion source of the RMH-2.

and their products, but John Beynon believed in the supreme value of the minor observation, the squiggle in the base line, the hint of structure in a peak. The fact that different metastable peaks had different shapes was explored and understood; the origin of composite peaks was traced, sometimes to contributions from collision-induced processes, whereas in other cases competitive reactions of the parent ion occur to give isomeric products [9]. The value of kinetic energy release measurements lies in the fact that it can give information on the properties of the transition state. By considering the magnitude of the released kinetic energy $T$ as a fraction of the potential energy made available as the transition state is converted to products, clues were obtained as to transition state structures and hence to reaction mechanisms.

In some instances, unusual mechanisms of delayed (metastable) dissociation could be uncovered. The small effect of temperature on the metastable fragmentation of $\mathrm{CH}_{4}^{+\cdot}$ to give $\mathrm{CH}_{3}^{+}$was used to show that $\mathrm{H}^{-}$loss occurs by tunneling through a centrifugal barrier [10]. Similarly, the effect of isotopic substitution on the energy release associated with $\mathrm{H}_{2}$ loss from $\mathrm{H}_{2} \mathrm{~S}^{+\cdot}$ was used to demonstrate that this reaction occurs slowly because it occurs by a forbidden predissociation from the ground state of $\mathrm{H}_{2} \mathrm{~S}^{+\cdot}$ to a repulsive excited state [11]. Even the energy of the classical crossing point of these electronic states could be measured. Direct, meticulous examination of the raw data was John's credo. If there appeared to be something new, then the instrument was pushed to its limits to make the observation; heated inlet systems were run to $350{ }^{\circ} \mathrm{C}$ or until they smoked, the accelerating voltage was run at its maximum-even when the source

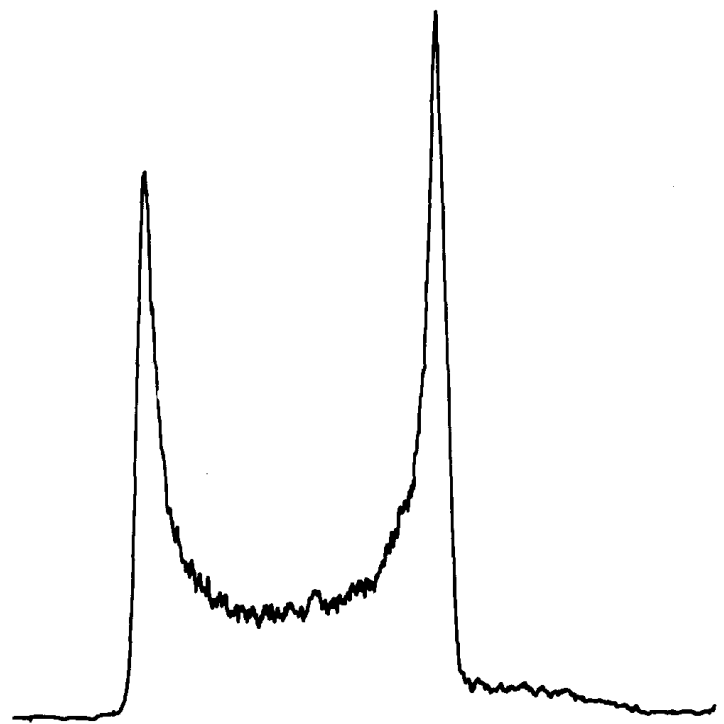

Figure 3. Slow scan through a single metastable peak in an ion kinetic energy spectrum.

then arced periodically-leading to losses of electronic components. $R C$ circuits were operated with time constants of $10 \mathrm{~s}$ to be consistent with scans that might last an hour to record a particular metastable peak profile (Figure 3). In a time when the acquisition of multiple MS/MS spectra per second is commonplace, this approach has a horse-and-buggy quaintness. But it was extremely effective; the merest hints of structure in the metastable peak for $\mathrm{H}_{3}^{+} \rightarrow \mathrm{H}^{+}+\mathrm{H}_{2}$ were recognized and reported [12]. The conclusion, that $\mathrm{H}_{2}$ was being formed in different vibrational states, was vindicated by later work with much higher energy resolution.

In the heat of such experiments, John Beynon was not an easy person to sit next to, in front of the instrument-the invariable place where data were interpreted as they emerged. (Note the harmony achieved when experiments were done slowly enough to allow thought and discussion in real time, rather than postacquisition.) His tendency was to make extreme, even outrageous, demands on the equipment, on his co-workers, and on himself. A strip chart recorder showing minor but annoying problems was tossed away; a lengthy, helpful review on a book chapter was similarly dumped for its overly critical tone.

The power of the measurement of kinetic energy release seemed unlimited. The multiplication factor in changing coordinate systems (energy release in the center-of-mass system, observation in the laboratory system) meant that thermochemical measurements of minute quantities (as small as 5 calories per mole) could be made with great precision [13]. At the other extreme, the same measurement yielded values of up to $8 \mathrm{eV}$ for the charge-separation reactions of doubly charged ions [14]. In an object lesson in the fact that significant observations are usually based on simple 
fundamentals, it was argued that these measurements reflect the nature of the transition state of a fragmenting ion. They could therefore be used, via Coulomb's law, to measure intercharge distances in fragmenting ions. Beynon taught his group another important lesson in this regard: Although bold in his approach and his reach toward conclusions, he insisted on subsequent thorough and systematic study to flesh out a phenomenon. Teodor Ast's Ph.D. thesis on kinetic energy releases associated with the dissociations of singly and multiply charged ions is an excellent illustration of this. In retrospect, the measurement of kinetic energy releases was a capability that may have arrived before its time. Although a few studies were done to compare theoretical calculations of transition state geometry and energy with energy-partitioning data derived from this method [15], this line of work was overtaken by the development of the immediately useful method of direct mixture analysis or MS/MS. It is interesting to note that the selection of the internal energy of a fragmenting metastable ion, which is controlled by the time scale of observations, is tantamount to state selection. The value of this method, however, was never completely successfully communicated to the chemical physics community at large. Nevertheless, it has served as a powerful method of distinguishing ion structures [16], especially after development of methods of converting the metastable peak shape to a distribution, $f(T)$, of kinetic energy release in the center of mass. The recent applications of these measurements to studies of the structure and fragmentation mechanisms of organometallic ions [17] provides additional evidence of their value.

\section{Collisional Processes}

Collision-induced dissociation (CID) of ions, both adventitious and intentional, can be traced back to the work of Thomson and Aston. After being assiduously avoided by mass spectrometrists, its value as a means of increasing "metastable" peak intensities was proposed almost simultaneously by Jennings [18] and by Haddon and McLafferty [19], although Kupriyanov and Perov [20] also deserve a large measure of credit. Jennings used a unique method of introducing collision gas: He gently baked the analyzer while he recorded metastable peaks. John Beynon employed an equally characteristic but very different approach. He located a suitable spot on the flight tube of the RMH-2 instrument and gave instructions for a simple gas introduction system to be attached. When it appeared that others were intent on fabricating a carefully designed device, and particularly when it became obvious that their scheme would require weeks, rather than be complete that evening as he wished, John took up the drill himself and punctured the mass spectrometer. Data were being taken early the next morning!

The combination of the ability to set the electric sector independently of the magnetic sector and the ability to study collision processes proved very useful. The thermochemistry of CID of both simple [21] and more complex [22] organic ions could be studied in great detail by utilizing both kinetic energy release measurements (peak widths) and kinetic energy losses (peak positions). The latter yield reaction endothermicities. In an experiment that illustrates the effective use of particular capabilities to do novel experiments, the electric sector was set at twice the value required to transmit ions generated in the ion source. Although this setting does not pass the main beam of stable ions, it transmits singly charged ions generated by charge exchange of doubly charged ions, because the kinetic energy change associated with this process is negligible but the product has twice the normal kinetic energy-to-charge ratio. The so-called $2 \mathrm{E}$ mass spectrum is therefore a selective scan for doubly charged ions [23]. At this point, serendipity met the prepared mind as one of the authors, in a confused early-morning attempt to perform an experiment of this type, halved the value of the electric sector voltage instead of doubling it. Signals resulted [24] due to the new process of charge stripping $\left(\mathrm{m}_{1}^{+} \rightarrow \mathrm{m}_{1}^{++}\right)$. These reactions could be studied collectively in the form of an E/2 mass spectrum, or the individual transitions could be scrutinized. The latter experiments, which focused on the threshold for doubly charged ion production, have been a rich source of thermochemical information, especially recently when their comparison with theory has been of interest to many [25]. The $-E$ or charge-inversion mass spectrum (conversion of a positive ion to a negative ion either in a single two-electron transfer collision or in two individual one-electron transfer events) was also studied and was found to be a useful source of information on the reacting electronic states of simple ions like $\mathrm{H}_{2} \mathrm{O}^{+}$. and $\mathrm{H}_{2} \mathrm{~S}^{+\cdot}$ [26]. At about this time, John Bowie made a short visit to Purdue and was stimulated to introduce the even more useful $+E$ mass spectrum, based on charge inversion of negatively charged ions [27].

A natural assumption might have been that, since metastable peaks and those due to CID make up at best a few percent of the abundance of the stable ions responsible for a mass spectrum, their measurement should suffer, relatively, from problems of poor sensitivity. In fact, this proved not to be the case, the poor signal being more than offset by the excellent signalto-noise ratios consequent upon removal of interfering peaks, the main source of "noise." The extremely large dynamic range of these measurements on metastable ions was illustrated and used in studies in which natural isotopic forms of ions occurring with abundances of $10^{-7}$ of the main beam were measured [28]. The principles on which this capability depends were later applied in measurements of trace components of mixtures, where the concept of chemical noise [29] has great significance.

\section{The MIKES}

During this period (1969-1972), it became obvious to the group at Purdue, as well as to others following their own unique lines of research, that studies on 


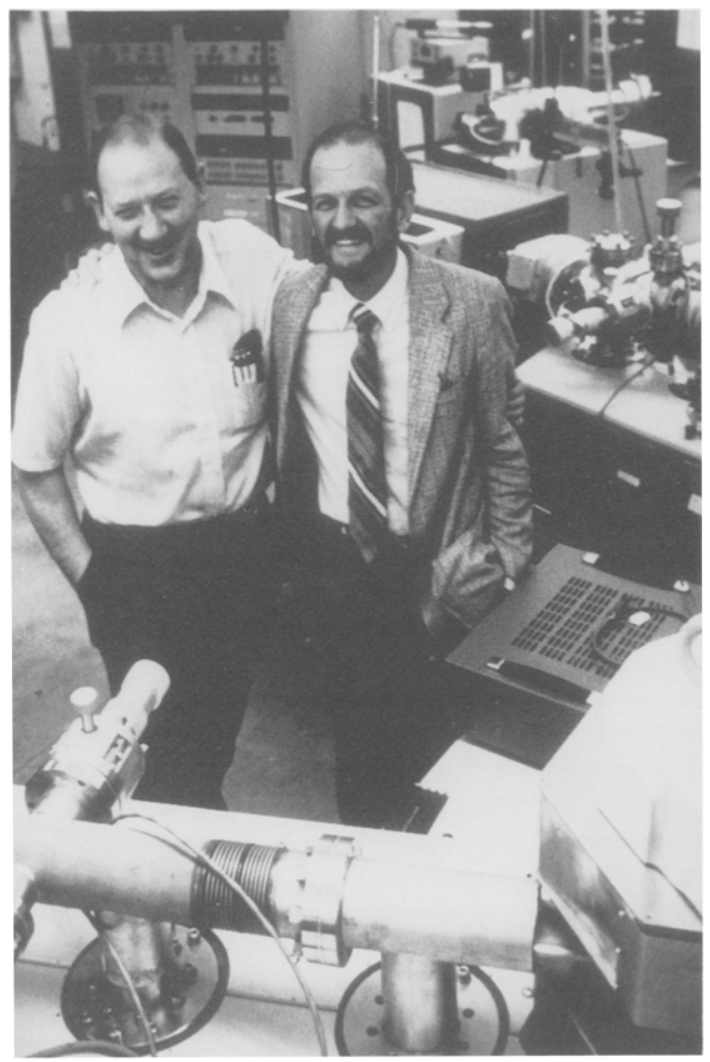

Figure 4. Precision machinist, the late Thomas $Y$. Ridley, with one of the authors, 1984.

metastable ions and the closely related process of CID would be greatly facilitated if the parent ion were mass-selected prior to dissociation and mass analysis of the products by the electric sector [30]. As it turned out, Brunnée's group at MAT, that of McLafferty at Cornell, and Beynon's at Purdue all pursued this course simultaneously and independently.

The concept was elaborated by Beynon and Cooks [31] in an article in Research and Development in 1971, the first fruit of what was to be a very close and intense collaboration. This geometry was not new [32], and even commercial versions of reverse-geometry instruments existed. What was novel was the suggestion that such a geometry would be useful for the study of metastable ions and the fact that mass-analyzed ions could be studied through their individual IKE spectra. This accounts for the choice of the term mass-analyzed ion kinetic energy spectrometry, or MIKES. The design of an instrument incorporating the high-energy resolution needed to examine detailed kinetic energy peak shapes was begun. Beynon wanted to saw the RMH-2 apart and so reverse the geometry. Some rough calculations and much persuasion convinced him that a far better approach would be to use components kindly provided by Associated Electronics Industries (AEI) Ltd.

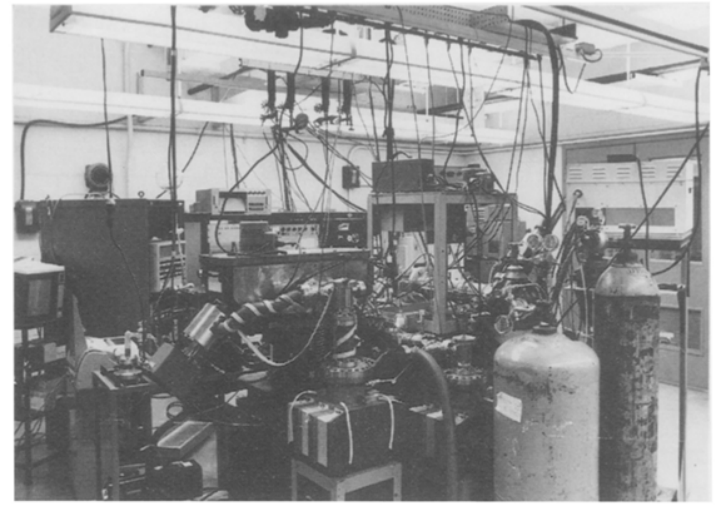

Figure 5. The MIKE spectrometer.

Machinist Tom Ridley (Figure 4) was to say repeatedly that the design of the MIKES instrument was presented to him on a single piece of paper bearing a hand-drawn sketch of the geometry. This piece of paper did indeed represent the focal point for turning the concept into a mass spectrometer. The ion optics were not entirely done in a seat-of-the-pants fashion, since Syd Evans of AEI (now Kratos) kindly provided calculations. Tom Ridley played a key role in the mechanical design, his training as a draftsman combining with his old-world and very thorough training as a precision machinist to make him a key participant in this and many later instrument developments. Ridley had built mass spectrometers previously, at McMaster University, with H. E. Duckworth. He had no lack of confidence, nor would he accept the possibility of his being wrong on an issue on which he had made a pronouncement, be it mathematics, chemistry, or material properties. He insisted on things being done "right" even as we were pushing for them to be done "now." The resulting conflict, which was to be replayed in each subsequent job, large or small, always resulted in a better, and especially a more flexible, mass spectrometer than would have been built otherwise. Ridley drew all the machine drawings, cut most of the metal himself, and provided us with instruments engineered for flexibility.

In a race with McLafferty to build the first instrument of this type, Beynon and Ridley clashed. Cooks mediated, and so began the (locally) famous teas when the scientist wanting a piece of work would be entertained at a strictly ritual tea in front of the lathes, drill presses, and grinders. The project was discussed, drawings examined, efforts to make changes resisted. More often than not Ridley was right, but he also compromised quietly, and the work proceeded rapidly.

The electronics were Amy's province, vacuum systems were Baitinger's, and a little over a year after work began, the instrument was complete (Figure 5) and the first spectra were being produced. Projects such as this are facilitated by intangibles-a rich tradition in instrumentation, team spirit, and the dedication of each member of the group. 


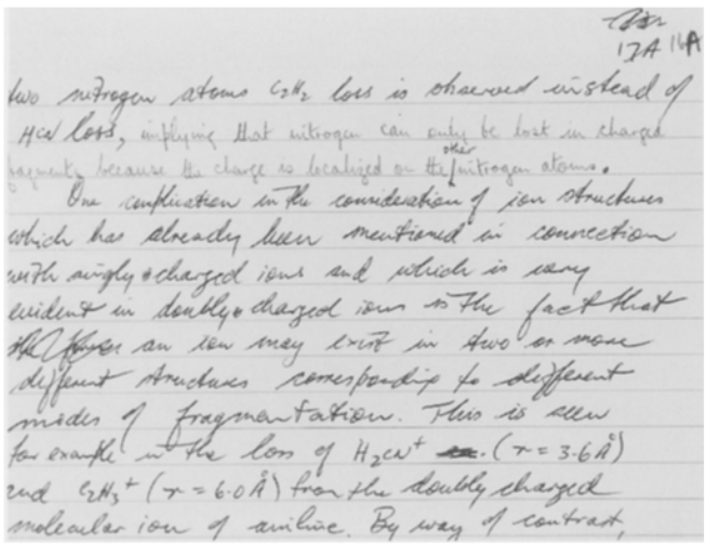

Figure 6. Manuscript of the book Metastable Ions (compare pp 192-193, ref 33)

Summers were a period of heightened activity because they coincided with John Beynon's being at Purdue. Although it could fairly be argued that we were stretched to follow the leads being provided by the IKES experiments and busy with the building of the MIKES, John felt that a book would have far more influence than the stream of papers then emerging from the laboratory. Planning took place by letter in the spring of 1982, and the book [33] was written during the three summer months. Work was divided among the four authors, but a unified text emerged, not least because Beynon, Caprioli, and Cooks would sit down together to scrutinize recent manuscript or, in some very productive sessions that engendered new research ideas, to actually write text as a threesome. Writing a book, in effect in one draft, proved relatively easy, reflecting as it did the by-product of a highly tuned research group. Figure 6 reproduces a fragment of this effort.

The reward for completing a chapter was the selection of the quotation with which it would begin. One of these has turned out to be a source of embarrassment. There being a limited number of chapters and a wealth of good quotes, Cooks combined two to make "None of this has any real meaning ... we have art in order not to die of the truth." The reference should have been to both Camus and Nietzsche, and the omission of Nietzsche's name was to be spotted years later by Steen Hammerum in conversation with a German philologist. A talk at the 1987 Asilomar Conference attempted to provide redress by demonstrating the connection of both authors to mass spectrometry and by advancing the thesis that Camus would have said the whole sentence-certainly he meant to-had Nietzsche not already used the words.

The MIKES instrument is both an ion kinetic energy spectrometer and a reverse-geometry mass spectrometer. It is a large instrument, its several components and their roles are easily visualized, and so it is an excellent instrument on which students can learn mass spectrometry. After 16 years and numerous modifications it is still running. It is estimated that some 70 people have taken data by using this particular instrument. Some 150 papers depend upon data recorded with it. It would be hard indeed to argue that NSF's investment of $\$ 20,000$ in capital funds in 1972 to develop this instrument was not money well spent.

Reverse-geometry instruments have subsequently been widely used in mass spectrometry. For example, the VG ZAB instrument, patterned after the MIKES, is estimated to have sold about 150 units ( $\$ 60$ million in today's dollars) and has played a crucial role in the development and applications of mass spectrometry.

\section{A Modus Operandus in Research}

While it is often argued that applications drive instrumentation, our experience has been otherwise. The MIKES instrument with its separatory power-for example, the ability to separate isotopically labeled forms of a molecular ion-engendered the direct analysis of mixtures by what has come to be known as tandem mass spectrometry, or MS/MS. This section is devoted to the consequences of the philosophy of research that took root at Purdue during John Beynon's tenure as illustrated by work of the last dozen years in the Aston Laboratory. It also focuses on the personal interactions upon which a research group depends.

\section{Direct Mixture Analysis}

Acquisition of a chemical ionization source for the MIKES shortly before John Beynon left Purdue, and the wish to change research directions after his departure led to the systematic development of a method of direct mixture analysis [34]. The key people involved were Rich Kondrat, a graduate student, and Terry Kruger, on sabbatical leave during 1975-1976 from nearby Ball State University. Direct analysis of individual components of the ionized mixture depends on their separation through mass analysis. No less important is the need for an ionization method that can convert compounds into ions that serve as their surrogates in the analysis. The groundwork on fundamentals of collisions either had been done or was proceeding simultaneously (as in the work summarized in the book Collision Spectroscopy [35]), and with the availability of the instrument they constituted a powerful force that cried out for practical applications.

An exciting period of almost frenzied activity began. It is worth recalling the spirit in the group that year. We felt, and every experiment seemed to confirm, that we had chanced upon some golden Nepalese valley, where every fanciful chemical desire was fulfilled. We rushed to introduce into the MIKES every conceivable type of mixture-plant leaf material, nutmeg, even strawberry jelly. Someone was unkind enough to remark that Cooks was the only one he knew who p---ed into his mass spectrometer (Figure 7). The ex- 


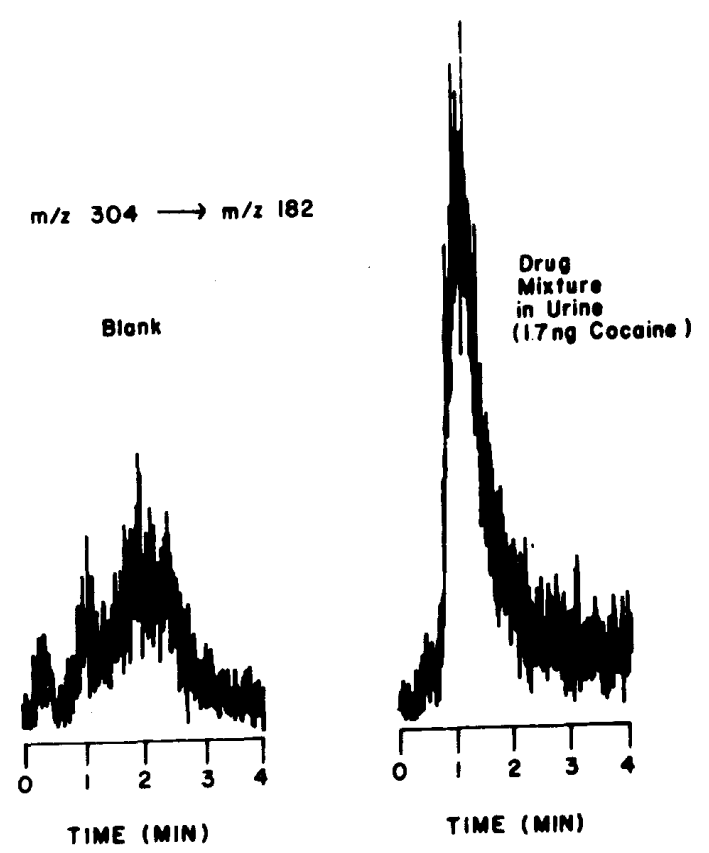

Figure 7. Direct mixture analysis, drugs in urine. (Presented at the ACS National Meeting, September 1979.)

citement of these results, and particularly the marvelous improvement in $\mathrm{S} / \mathrm{N}$ ratio through elimination of chemical noise, led to a series of exhortative seminars on the topic that divided audiences sharply into total skeptics and total believers. Our wilderness experience in preaching direct mixture analysis came to an end when we were joined by welcome allies. Notable among these were Chris Enke and Rick Yost [36], with whom we held a pivotal discussion over breakfast in the Kellogg Center at Michigan State University in February 1977; Don Hunt, who quickly applied the method to important problems [37]; and Fred McLafferty, who had been pursuing parallel investigations on ion structures in mixtures [38]. Thoreau's comment "of course I exaggerate, it's the only way to tell the truth" proved eerily true as the capabilities of MS/MS proved the equal of even the most fanciful claims. Much of this story can be found in two reviews, both in Analytical Chemistry, the first a little-cited article from 1976 [34] and the second a well-known 1978 paper [39]. A key feature of the technique, the improvement in $\mathrm{S} / \mathrm{N}$ ratio consequent upon reduction in chemical noise, was not readily accepted. The fact that the more complex a mixture the easier it is to obtain a daughter spectrum characteristic of a trace component that constitutes the major component at a particular $\mathrm{m} / \mathrm{z}$ value often escaped recognition.

The presumed limitation of the method to targeted compound analysis led us to attempt to identify new compounds in complex mixtures. Successes came readily with the discovery of new alkaloids [40] but were not limited to this class of biomolecules $[41,42]$.
This motivation also contributed to the development of alternative scan modes, including the neutral loss scan [43], designed to obtain information on groups of functionally related but not individually targeted compounds. Of course, harsh reality also crept in, especially in early attempts to apply the methodology to the analysis of modified (methylated) ribonucleosides [44]. The thermolysis step used to convert RNA to fragments suitable for ionization caused unsuspected isomerization. Only much later, by using enzymatic degradation and a combination of LC and MS/MS, did we succeed in quantitating trace levels of modified nucleosides in mixtures [45].

\section{Hybrids and Ion Traps: Working with Others}

By 1978 the power of the MS/MS method for direct mixture analysis was clear. It was also apparent that the reverse-geometry MIKES instrument had severe limitations. (Some of these were lifted by triple quadrupoles, which were introduced by Enke and Yost in 1979 [46] and were available commercially by 1981.) In view of this, we set out in early 1978 to design and build an improved MS/MS instrument. Gary Glish accepted this assignment as a Ph.D. project, and Finnigan Corporation contributed components and, through Mike Story, advice. The instrument [47], of $B Q Q$ geometry, was perhaps unique in being constructed in modular fashion with the intent of utilization in a variety of configurations for various purposes including ion-surface collisions (see below).

The BQQ instrument provided another object lesson in instrumentation. By the late 1970s, magnet technology in mass spectrometry lagged behind the state of the art. The state of the art employed nonnormal entry, fringe field correctors, laminated magnet construction, and even inhomogeneous fields. These improvements had been driven by the demands for beam-steering magnets in accelerators, and both the academic community and the manufacturers of mass spectrometers had failed to follow these developments. A chance meeting in San Francisco between Jon Amy and Hilton McGlavish, vice president of ANAC, a small New Zealand-based magnet company, bridged the gap, and by December 1979 the first ANAC magnet was in use in a mass spectrometer, the $B Q Q$ instrument.

The success of the BQQ led us to build a BEQQ instrument [48] that combined the advantages of highresolution mass spectrometry with capabilities for lowand high-energy MS/MS. This instrument was built in close cooperation with Finnigan MAT, with Alan Schoen, a recent Ph.D. from the Aston Laboratory, returning to spend two years (mid-1982 to 1984) working on the project. The work was a cooperative venture with the Bremen Laboratories of Finnigan MAT, Peter Dobberstein being especially closely involved. In a project of this nature, we were to learn what so many have learned before: that good communications are a key to success. Weekly transatlantic calls were made, 
telephone notes were written up, and hard copies were exchanged. The result was that everyone involved had a clear idea of the status and direction of the project at all times. Given the contributions of the Bremen team to the project, it can perhaps be taken as a tribute to the scientific if not the economic achievements of Finnigan that hybrids are now very successful instruments (most of which are manufactured by VG Instruments!).

Many people graduated from the Aston Laboratory to take positions in industry. A desire to have them learn about the industrial environment plus the wish to stimulate colleagues in industry and to benefit in turn from their knowledge and abilities led us to set up an informal personnel exchange program. This was in full swing by the late 1970s and was an attempt, perhaps idealistic, to forge joint research endeavors with industry. Visits were of short duration, both to and from industry, and many led to publications. The strong ties developed during this program continue to the present. In fact, this personnel exchange program was a predecessor to the Purdue chemistry department's Industrial Associates Program, which retained the emphasis on joint research.

The generations of graduate students come so quickly that what is a bold experiment one year is seen as the norm the next. Our experiences with personnel exchange thus fueled, we were soon offering graduate students sabbaticals! These 3-6-month periods provide students with opportunities to participate in technology transfer, relief from the midwest, and an occasion to work within strict time limits in a foreign environment. Examples include visits by Jenny Brodbelt to Dow Chemical, Midland, to study membrane interfaces [49]; by John Louris to Finnigan, San Jose, to build the prototype ion trap mass spectrometer (ITMS) [50]; by Mark Bier to Finnigan to build a tandem quadrupole instrument for ion-surface collisions [51]; and by Kevin Schey to Justus Liebig's University, Giessen, to build a tandem time-of-flight instrument for ion-surface collisions [52].

Making optimum use of available opportunities includes working well with people at one's home institution who can have a powerful effect, positive or negative, on research progress. Two groups that are particularly important in universities are those who work in the physical plant and the purchasing department. To harness the talents and energy of these groups in your cause makes good sense; to do otherwise is to ask for bottlenecks in the progress of research.

Purdue's purchasing agents, especially Noel Reen, have been invaluable in locating cost-effective products and expeditious means of acquiring them. Our practice has been to bring these people in at the planning stage of a new project. The watchword is: No surprises. Similarly, university physical plants represent a natural target of resentment for the researcher in a hurry. After all, they deal in old-fashioned commodities like three-phase $Y, 240 \mathrm{~V}$ power that comes in ampere amounts while we look for nanoamps in $5-\mathrm{V}$ binary states. Yet show a little interest and a little respect, and watch your project be done first, with pride.

\section{Collisions with Surfaces}

Collision phenomena had come to occupy a large part of the interest of the Aston Laboratory by 1977, so it was natural to follow the lead of the physics community in moving from gaseous to surface collisions. The beam/foil experiments of White et al. [53] were important in this respect, as was the influential book by Kaminsky [54]. Our first experiment of this type, reported in 1975, used glancing collisions with surfaces introduced into the first or second field-free region [55] or with the walls of the flight tube itself [56]. Performance in inducing dissociation was disappointing, although charge-changing collisions of organic ions were readily effected, a result that paralleled observations on atomic systems then being studied with angular resolution [57].

These experiences prepared us to embark on a rigorous study of organic ion-surface collisions as soon as the BQQ hybrid instrument became available. The flexibility of this instrument allowed the geometry changes necessary for SID to be implemented with great ease, once the initial aim of characterizing electronvolt-range CID experiments had been accomplished by Gary Glish, working with fellow student and subsequent coworker at Oak Ridge, Scott McLuckey [58].

The BQ yielded SID daughter spectra of excellent reproducibility in the hands of Mike DeKrey and $\mathrm{Ab}$ dul Mabud [59]. Surface collisions are more effective at energy deposition than are gaseous collisions; moreover, the internal energy distribution is relatively narrow and easily controlled [60]. It was soon found that charge-transfer reactions accompanied ion-surface collisions and that SID is an excellent complementary method to CID in ion structural characterization [61, 62].

One of the great pleasures in research is the possibility of working with people from many different nations. The visits of established scientists are an important component of graduate student education, and we were fortunate to have capable people from Finland, Italy, Yugoslavia, the German Democratic Republic, and the People's Republic of China work with us on ion-surface collisions.

There was another dimension to our interests in ion-surface collisions that again illustrates some general truths, the most important being that a grossly underfunded instrument is worse than none at all. We refer here to the original soft-lander, an instrument of bold concept-tailoring of surfaces using specific polyatomic reagent ions through chemical reactions at very low collision energy-but poor performance. High ion currents were produced in a plasma source, but the high operating temperature restricted the types of organic ions that could be produced. Mass selection 
was achieved with a Wien filter, a simple and cheap method but one that afforded line-of-sight access from the source to the target region. The encouraging results that were obtained [63] were not enough to rescue the project. Nevertheless, good experience was gained at decelerating ion beams to low energies, and the highly effective $B Q Q$ deceleration system-an intuitive, not a formal, ion optical design-owed something to this experience.

With the construction of the appropriate instruments, the topic of polyatomic ion-surface collisions has subsequently blossomed. Not the least pleasing result is the observation $[64,65]$ of reactive collisions between the incident ion and surface molecules.

\section{Conclusion}

What is it about an individual, a place, or a time that spawns the birth of new techniques? The answer to that question involves the understanding of creativity and the creative process. John Beynon has been involved in many fundamental and instrumental advances. The development of the MS-9 and ZAB series of mass spectrometers as well as the development of the IKES and MIKES techniques described here bear his seal. Those who have worked closely with him recognize several characteristics:

The ability to focus one's entire attention upon a problem, bringing to bear a broad background of experience and training.

The recognition of problems of importance that require a solution.

The appreciation that team efforts are often required, and that this calls for a balance between strong leadership and recognition of each individual.

This leads to four basic rules:

1. Do an experiment now, with equipment on hand, rather than trying to design the perfect experiment.

2. Keep experiments as simple as possible.

3. Be on good terms with the media with which you are working.

4. Have fun in what you are doing.

With these characteristics and credo, Beynon founded a tradition at Purdue. A dozen other instruments have been built, new methodologies have been developed, and several generations of students have been trained in the Aston Lab.

No conclusion to this paper could be more appropriate than Abelson's words, "Instruments shape research, determine what discoveries are made, and perhaps even select the types of individuals likely to succeed as scientists" [66]. It seems to us that an in- frastructure is the bedrock upon which modern chemical research depends. This infrastructure includes facilities for acquiring, maintaining, and modifying instrumentation. It also includes the human infrastructure, the individual research group. This organic unit thrives on mutual respect, complementary talents, and opportunities for growth. Good people are grown, not discovered; made, not imported!

\section{Acknowledgments}

The National Science Foundation has funded the Aston Laboratory since 1971, currently through NSF grant 87-21768. Their support is greatly appreciated. Finnigan Corp. and Dow Chemical have been long-standing industrial partners.

\section{References}

1. Beynon, J. H.; Baitinger, W. E.; Amy, J. W.; Komatsu, T. Int. J. Mass Spectrom. Ion Phys. 1969, 3, 47.

2. Struck, A. H.; Major, H. W. Presented at the 17th Annual Conference on Mass Spectrometry and Allied Topics, Dallas, Texas, May 1969; paper 36.

3. Beynon, J. H.; Caprioli, R. M.; Baitinger, W. E.; Amy, J. W. Int. J. Mass Spectrom. Ion Phys. 1969, 3, 313.

4. Beynon, J. H.; Cooks, R. G. J. Phys. 1974, 7, 10.

5. Cooks, R. G.; Beynon, J. H. J. Chem. Educ. 1974, 51, 437.

6. Beynon, J. H.; Saunders, R. A.; Williams, A. E. Z. Naturforsch. 1965, 20a, 180.

7. Shapiro, R. H.; Tomer, K.; Beynon, J. H.; Caprioli, R. M. Org. Mass Spectrom. 1970, 3, 1593.

8. Eadon, G.; Djerassi, C.; Beynon, J. H.; Caprioli, R. M. Org. Mass Spectrom. 1971, 5, 917.

9. Beynon, J. H.; Bertrand, M.; Cooks, R. G. J. Am. Chem. Soc. 1973, 95, 1739.

10. Solka, B. H.; Beynon, J. H.; Cooks, R. G. J. Phys. Chem. 1975, 79, 859.

11. Terwilliger, D. T.; Cooks, R. G.; Beynon, J. H. Int. J. Mass Spectrom. Ion Phys. 1975, 18, 43.

12. Cooks, R. G.; Beynon, J. H. Chem. Commun. 1971, 1282.

13. Cooks, R. G.; Kim, K. C.; Beynon, J. H. Chem. Phys. Lett. 1974, 26, 131.

14. Beynon, J. H.; Caprioli, R. M.; Richardson, J. W. J. Am. Chem. Soc. 1971, 93, 1852.

15. Krause, D. A.; Day, R. J.; Jorgensen, W. L.; Cooks, R. G. Int. J. Mass Spectrom. Ion Phys. 1978, 27, 227.

16. Holmes, J. L. Org. Mass Spectrom. 1985, 20, 169.

17. Hanratty, M. A.; Beauchamp, J. L.; Illies, A. J.; van Koppen, P.; Bowers, M. T. J. Am. Chem. Soc. 1988, 110, 1.

18. Jennings, K. R. Int. J. Mass Spectrom. Ion Phys. 1968, 1, 227.

19. Haddon, W. F.; McLafferty, F. W. J. Am. Chem. Soc. 1968, 90,4745 .

20. Kupriyanov, S. E.; Perov, A. A. Zh. Fiz. Khim. 1968, 42, 857.

21. Jones, E. G.; Beynon, J. H.; Cooks, R. G. J. Chem. Phys. 1972, 8, 3207 .

22. Cooks, R. G.; Hendricks, L.; Beynon, J. H. Org. Mass Spectrom. 1975, 10, 625.

23. Ast, T.; Beynon, J. H.; Cooks, R. G. Org. Mass Spectrom. $1972,6,749$.

24. Ast, T.; Beynon, J. H.; Cooks, R. G. J. Am. Chem. Soc. 1972, 94,6611

25. Koch, W.; Manquin, F.; Stahl, D.; Schwarz, H. Chimia 1985, $39,376$.

26. Keough, T.; Beynon, J. H.; Cooks, R. G. I. Am. Chem. Soc. 1973, 95, 1695.

27. Bowie, J. H.; Blumenthal, J. J. Am. Chem. Soc. 1975, 97, 2959. 
28. Beynon, J. H.; Corn, J. E.; Baitinger, W. E.; Amy, J. W.; Benkeser, R. A. Org. Mass Spectrom, 1970, 3, 191.

29. Busch, K. L.; Cooks, R. G. In Tandem Mass Spectrometry; McLafferty, F. W., Ed.; Wiley-Interscience: New York, 1983; Ch. 2.

30. Beynon, J. H.; Cooks, R. G.; Amy, J. W.; Baitinger, W. E.; Ridley, T. Y. Anal. Chem. 1973, 45, 1023A.

31. Beynon, J. H.; Cooks, R. G. Res/Develop. 1971, 22, 26.

32. White, F. A.; Rouke, F. M.; Sheffield, J. C. Appl. Spectrosc. 1958, 12, 46.

33. Cooks, R. G.; Beynon, J. H.; Caprioli, R. M.; Lester, G. R. Metastable Ions; Elsevier: Amsterdam, 1973.

34. Kruger, T. L.; Litton, J. F.; Kondrat, R. W.; Cooks, R. G. Anal. Chem. 1976, 48, 2113.

35. Cooks, R. G. In Collision Spectroscopy; Cooks, R. G., Ed.; Plenum: New York, 1978.

36. Yost, R. A.; Enke, C. G. J. Am. Chem. Soc. 1978, 100, 2274.

37. Hunt, D. F.; Shabanowitz, J.; Giordani, A. B. Anal. Chem. $1980,52,386$.

38. McLafferty, F. W.; Brockhoff, F. M. Anal. Chem. 1978, 50, 69.

39. Kondrat, R. W.; Cooks, R. G. Anal. Chem. 1978, 50, 81.

40. Kruger, T. L.; Cooks, R. G.; McLaughlin, J. L.; Ranieri, R. L. J. Org. Chem. 1977, 42, 4161.

41. Kondrat, R. W.; McClusky, G. A.; Cooks, R. G. Anal. Chem. 1978, 50, 2017.

42. McClusky, G. A.; Cooks, R. G.; Knievel, A. M. Tetrahedron Lett. 1981, 4471.

43. Zakett, D.; Schoen, A. E.; Kondrat, R. W.; Cooks, R. G. J. Am. Chem. Soc. 1979, 101, 6781.

44. Schoen, A. E.; Cooks, R. G.; Wiebers, J. L. Science 1979, 203, 1249.

45. Cooks, R. G.; O'Lear, J. R.; Chand, C.-J. J. Res, Natl. Bur. Stand. 1988, 93, 419.

46. Yost, R. A.; Enke, C. G. Anal. Chem. 1979, 51, 1251A.

47. Glish, G. L.; McLuckey, S. A.; Ridley, T. Y.; Cooks, R. G. Int. J. Mass Spectrom. Ion Phys. 1982, 41, 157

48. Schoen, A. E.; Amy, J. W.; Ciupek, J. D.; Cooks, R. G.;
Doberstein, P.; Jung, G. Int. J. Mass Spectrom. Ion Processes 1985, 65, 125.

49. Brodbelt, J. S.; Cooks, R. G.; Tou, J. C.; Kallos, G. J.; Dryzga, M. D. Anal. Chem. 1987, 59, 454

50. Louris, J. N.; Cooks, R. G.; Syka, J. E. P.; Kelley, P. E.; Stafford, G. C.; Todd, J. F. J. Anal. Chem. 1987, 59, 1677.

51. Bier, M. E.; Amy, J. W.; Cooks, R. G.; Syka, J. E. P.; Ceja, P.; Stafford, G. Int. J. Mass Spectrom. Ion Processes 1987, 77, 31.

52. Schey, K.; Cooks, R. G.; Grix, R.; Wollnik, H. Int. J. Mass Spectrom. Ion Processes 1987, 77, 49.

53. White, F. A.; Rouke, F. M.; Sheffield, J. C. Rev. Sci. Instrum. 1958, 29, 182.

54. Kaminsky, M. Atomic and Ionic Impact Phenomena on Metal Surfaces; Academic: New York, 1965.

55. Cooks, R. G.; Terwilliger, D. T.; Ast, T.; Beynon, J. H.; Keough, T. J. Am. Chem. Soc. 1975, 97, 1583.

56. Cooks, R. G.; Ast, T.; Beynon, J. H. Int. J. Mass Spectrom. Ion Phys. 1975, 16, 348.

57. Tolk, N. H.; Tully, J. C.; Heiland, W.; White, C. W., Eds.; Inelastic Ion-Surface Collisions; Academic: New York, 1977.

58. McLuckey, S. A.; Glish, G. L.; Cooks, R. G. Int. J. Mass Spectrom. Ion Phys. 1981, 39, 219.

59. Mabud, M. A.; DeKrey, M. J:; Cooks, R. G. Int. J. Mass Spectrom. Ion Processes 1985, 67, 295.

60. DeKrey, M. J.; Kenttämaa, H. I.; Wysocki, V. H.; Cooks, R. G. Org. Mass Spectrom. 1986, 21, 193.

61. Vainiotalo, P.; Kenttämaa, H. I.; O'Lear, J. R.; Cooks, R. G. J. Am. Chem. Soc. 1987, 109, 3187.

62. Mabud, M. A.; Ast, T.; Verma, S.; Jiang, X. J.; Cooks, R. G. J. Am. Chem. Soc. 1987, 109, 7597.

63. Franchetti, V.; Solka, B. H.; Baitinger, W. E.; Amy, J. W.; Cooks, R. G. Int. J. Mass Spectrom. Ion Phys. 1977, 23, 29.

64. Ast, T.; Mabud, M. A.; Cooks, R. G. Int. J. Mass Spectrom. Ion Processes 1988, 82, 131.

65. Vincenti, M.; Cooks, R. G. Org. Mass Spectrom. 1988, 23, 317.

66. Abelson, P. Am. Sci. 1986, 74, 182. 